MILITARY TECHNICAL COLLEGE CAIRO - EGYPT

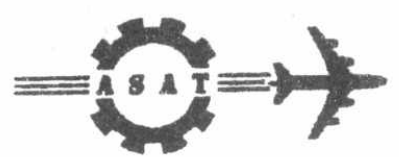

$7^{\text {th }}$ INTERNATIONAL CONF. ON AEROSPACE SCIENCES \& AVIATION TECHNOLOGY

\title{
THE BEHAVIOR OF POLYCRYSTALLINE ALUMINUM \\ UNDERGOING CREEP-FATIGUE INTERACTION \\ AT AMBIENT TEMPERATURE
}

\section{R.M. RAMADAN ${ }^{1}$}

\begin{abstract}
The behavior of polycrystalline aluminum under creep-fatigue interaction at ambient temperature was investigated using optical and transmission electron (TEM) microscopes. The variation in the flow stress with the cumulative strain was determined and correlated with the stages of the development of the dislocations structure. Fracture surfaces were observed by scanning electron microscope (SEM). The obtained results showed that fatigue striation fracture was the dominant fracture mechanism. Moreover, there was no differences observed between the evolved substructure at the steady state of creep-fatigue interaction and the reported results of the steady state of either monotonic creep at high temperature or cyclic straining to large cumulative strain at ambient temperature. It is concluded that the same mechanisms work in either creep and fatigue are working simultaneously during creep-fatigue interaction that enhances the failure.
\end{abstract}

\section{KEY WORDS}

Creep-fatigue interaction, Polycrystalline aluminum, Dynamic recovery, Fracture mechanisms.

- Associate Professor, Dpt. of Metallurgy, Faculty of Petro.\&Min. Eng., Suez Canal University, Suez, Egypt. 


\section{INTRODUCTION}

Under service conditions many structural components are subjected to combinations of static and dynamic loads. The development of engineering materials that sustain such loading conditions is a complex problem. The difficulty of the problem is mainly due to the fact that the deformation behavior of materials under general loading conditions often does not follow the prediction of the conventional separately creep and fatigue test results. Several articles on the subject have examined the importance of the creep-fatigue interaction[1-7].

There have been two approaches to the problems of deformation behavior under cyclic loading. In the first approach, the loading conditions actually encountered in service are simulated and the test data directly useful to explain the deformation behavior for specific material are obtained. In the second approach, the basic aspects of the loading conditions are investigated using a model material in order to understand the fundamental mechanisms of the simulation creep-fatigue interaction. In the second approach, on one hand, more attentions are given to the evolved dislocations structure and its role in the material behavior under the loading conditions. On the other hand, the failure mechanisms under creep-fatigue interaction examined carefully and correlated to the accumulated damage over all the cyclic creep life of the model material.

In the present study, the model material chosen is polycrystalline commercial pure aluminum. The choice was made on the basis that aluminum represents with its high stacking fault energy and relatively high homologous temperature at ambient temperature. Both of those ease up the nonconservative movement of dislocations at ambient temperature, thereto, high temperature tests can be avoided. Moreover, there is considerable amount of reported data from creep tests and fatigue tests of aluminum[8]. These data should be helpful when dealing with combined problem of creep-fatigue interaction.

\section{EXPERIMENTAL PART}

Aluminum was supplied as sheet of $0.9 \mathrm{~mm}$ thick containing $0.41 \% \mathrm{Fe}, 0.09 \%$ $\mathrm{Si}, 0.05 \% \mathrm{Mn}, 0.3 \% \mathrm{Cu}, 0.03 \% \mathrm{Mg}$ and $0.02 \% \mathrm{Ti}$. The received sheet was cut into strips of $15 \mathrm{~mm}$ width and $300 \mathrm{~mm}$ length that annealed at $350{ }^{\circ} \mathrm{C}$ for one hour followed by air cooling.

Creep-fatigue interaction test was carried out on a cyclic bending/unbending rig which introduced cyclic bending strain under positive superimposed stress $\left(\sigma_{s s}\right)$. The used rig is explained in details elsewhere[4]. Cyclic strain was introduced when a strip was running around the used pulley of $50 \mathrm{~mm}$ diameter. A bending 
strain amplitude $\left(\varepsilon_{\mathrm{p}}\right)$ of 0.018 was introduced each cycle. Superimposed stresses of $4.5,13.3$ and $22.2 \mathrm{MPa}$ were applied. A specific length of $150 \mathrm{~mm}$ was marked at the middle portion of the strip to determine the resultant strain. Two strips were used to introduce certain number of cycles, then two tensile specimens taken from each strip. Tensile test was carried out using Instron tensile machine 4208 at cross head speed of $0.05 \mathrm{~cm} / \mathrm{min}$. A Nephot 21 optical microscope and Joel 200 TEM were used. The fracture surfaces of the failed specimens were observed using SEM Joel JSM-T100.

\section{RESULTS \& DISCUSSION}

The cyclic creep behavior relative to the static creep behavior can be vary considerably. Figure 1 displays the cyclic creep curves of the investigated material. It is interesting to mention that no considerable creep strain achieved at the applied superimposed stresses at the absent of cyclic straining (static creep) after a period of $72 \mathrm{hr}$. These result indicates that the additional fatigue greatly enhances the deformation process. This behavior termed cyclic strain acceleration[9]. In order to follow up the behavior of the investigated material under creep-fatigue interaction condition both tensile test and metallography examination were carried out. Figure 2 shows the variation of the flow stress with the accumulated cyclic strain. It can be observed that cyclic creep is associated with strain hardening that retards the creep strain over the steady state stage, Fig 1 . The steady state stage diminishes with increasing the $\sigma_{\text {ss. }}$ during creep-fatigue interaction test, Fig 1. On the other hand, the variation of the flow stress of the deformed specimens versus the number of cycles displays a saturation stage that established after few cycles and continued up to failure, Fig 2. To avoid confusion through the present discussion steady state will be used to mention both steady state stage, Fig 1 , and saturation stage, Fig 2.

Metallography results of cyclically crept specimens at mean superimposed stresses of $4.5,13.3$ and $22.2 \mathrm{MPa}$ up to $50 \%$ of the specimens life are Shown in Figs $3-5$ respectively. There are two chief features can be recognized regardless the level of the applied $\sigma_{\mathrm{ss}}$. Firstly, the presence of slip bands and secondly, cavities which distributed over the grain interiors and along the grain boundaries. The amount of created cavities increases with the applied $\sigma_{\mathrm{ss}}$, Figs 3-5. In order to obtain better view of the created cavities, SEM was used. Figure 6 shows the deformed structure after $7 \mathrm{~min}$. at $\sigma_{\mathrm{ss}}$ of $13.3 \mathrm{MPa}$. Cavities are observed to coalesces together forming microcracks that propagated through the grain's body or along the grain boundaries. 


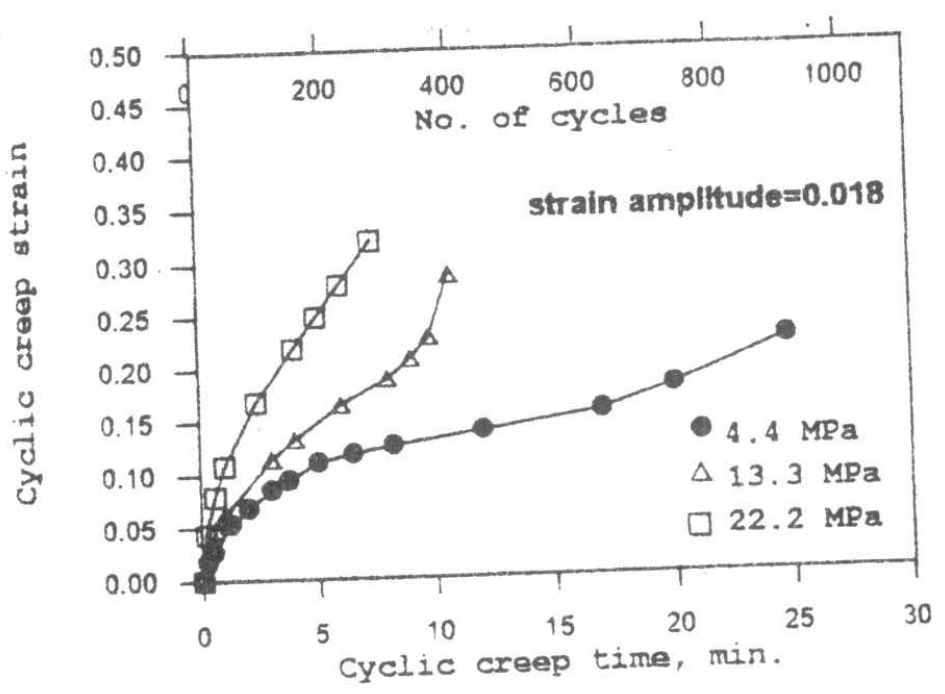

Fig. 1: Cyclic creep strain of aluminum.

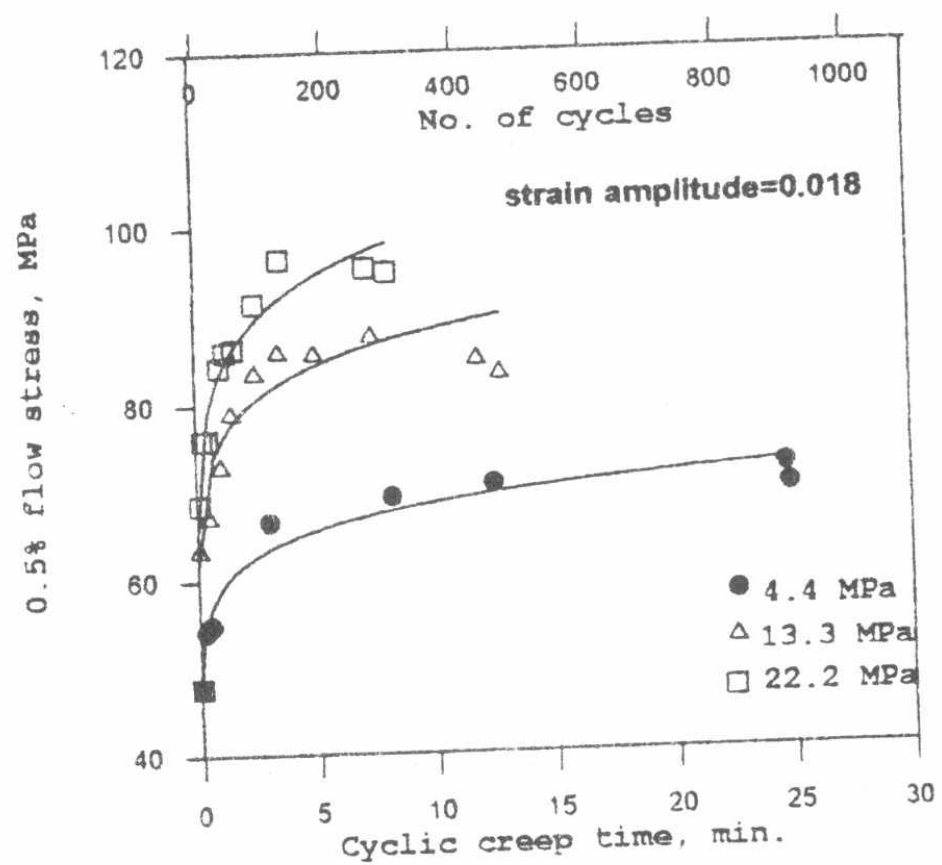

Fig. 2: Cyclic creep behaviour of aluminum. 


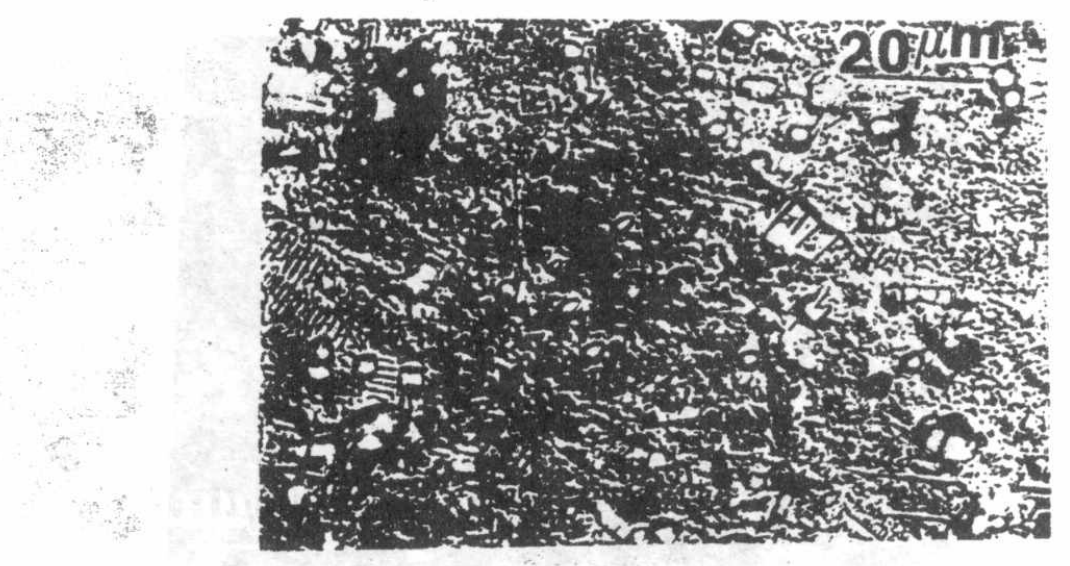

Fig.3: Microstructure of cyclic crept specimen for 13 min., $\left(\sigma_{\mathrm{ss}} 4.4 \mathrm{MPa}\right)$.

Dislocation structural observations were made covering both the transient and the steady state stages. Steps in the evolution of the dislocation structure with cyclic creep strain at $\sigma_{\mathrm{ss}}$ of $13.3 \mathrm{MPa}$ are shown in Fig 7. The dislocation structure of the initial annealed material displays few stray dislocations. At the commence of the transient stage high dislocation destiny regions developed, Fig $7 \mathrm{~b}$, dislocation bundles and dislocation free zones. Further straining is observed to refine the high dislocations zones continuously. Cellular structure evolved at the commence of the transient stage, Fig 7c. The contrast difference between the developed cells is observed to increase with straining, Figs $7 \mathrm{c}$ and $\mathrm{d}$. It seems that over the transient stage dislocation omitted from dislocation bundles which can be annihilated with opposite dislocation sign or entangled into dislocation walls. The dislocation structure of the failed specimen shows sharp cells and concentrated deformation zones. The concentrated deformation zones is observed to contain finer substructure than the matrix, Fig 7e. At this stage this fine substructure can be called subgrains because the misorintation difference between them is found to be as high as $7^{\circ}$. The observed dislocation structures illustrate that the steady state is a result of the establishment of balancing between the strain hardening rate induced by creep-fatigue interaction straining and the dynamic recovery. The main driving force for dynamic recovery is the gain in the internal energy when the high energy configuration form of dislocations transformed into the low energy configuration form through annihilation of dissimilar dislocations and the rearrangement of the surplus similar sign dislocations into cellular structure. The prerequisite condition for dynamic recovery, dislocations climb and dislocations cross slip are available. Climb is a thermal assisted process. On one side, at ambient temperature the homologous temperature of deformation is 0.32 which eases the climb process. On the other side, the high stacking fault energy of aluminum does not allow dislocation dissociation. Both fatigue and creep increase the density of vacancies 


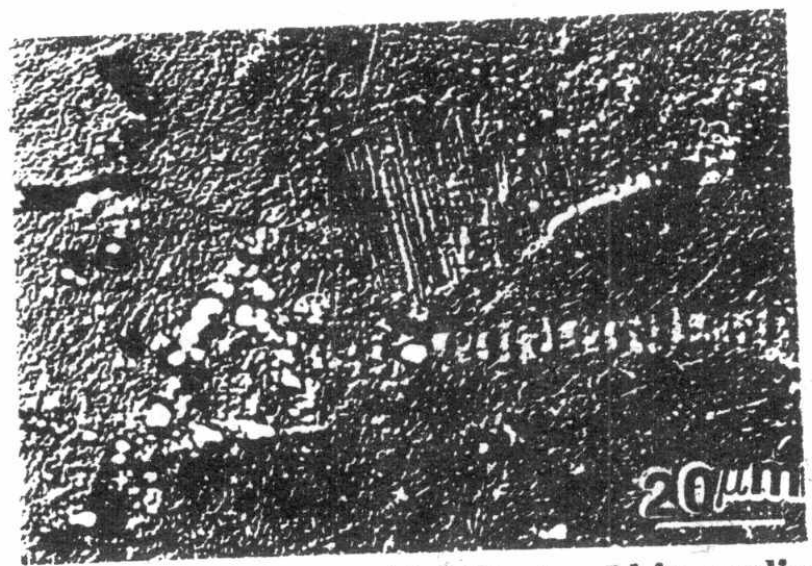

Fig.4: Slip bands and voids developed in cyclic crept specimen for $7 \mathrm{~min}$. $\left(\sigma_{\mathrm{ss}}=13.3 \mathrm{MPa}\right)$.

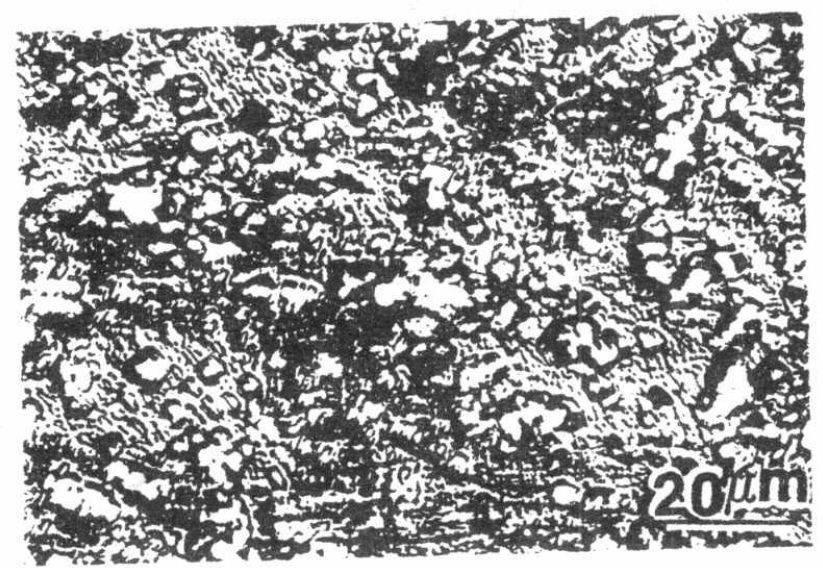

Fig.5: Slip bands and voids developed in cyclic crept specimen for $7 \mathrm{~min}$. $\left(\sigma_{\mathrm{ss}}=22.2 \mathrm{MPa}\right)$.

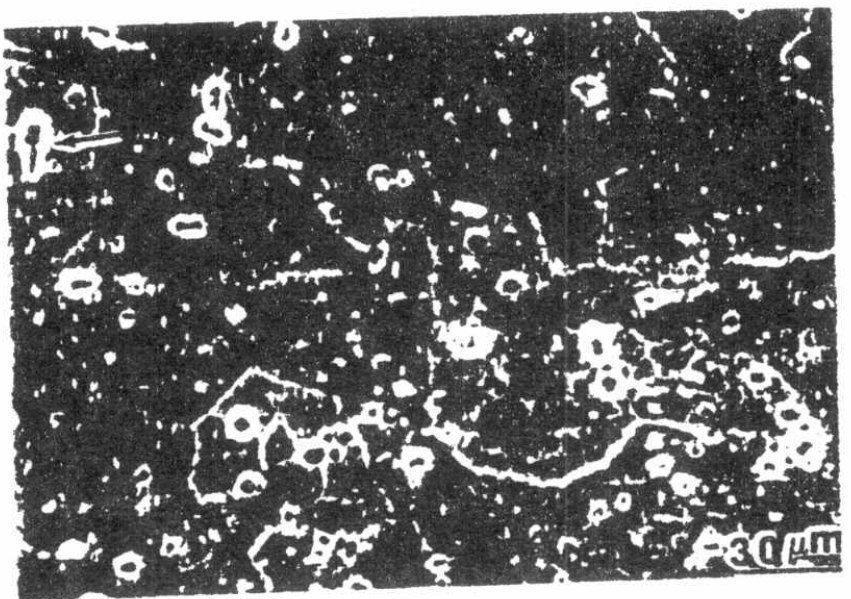

Fig.6: SEM micrograph showing voids developed in cyclic crept specimen for $7 \mathrm{~min}$. $\left(\sigma_{\mathrm{ss}}=13.3 \mathrm{MPa}\right)$. 

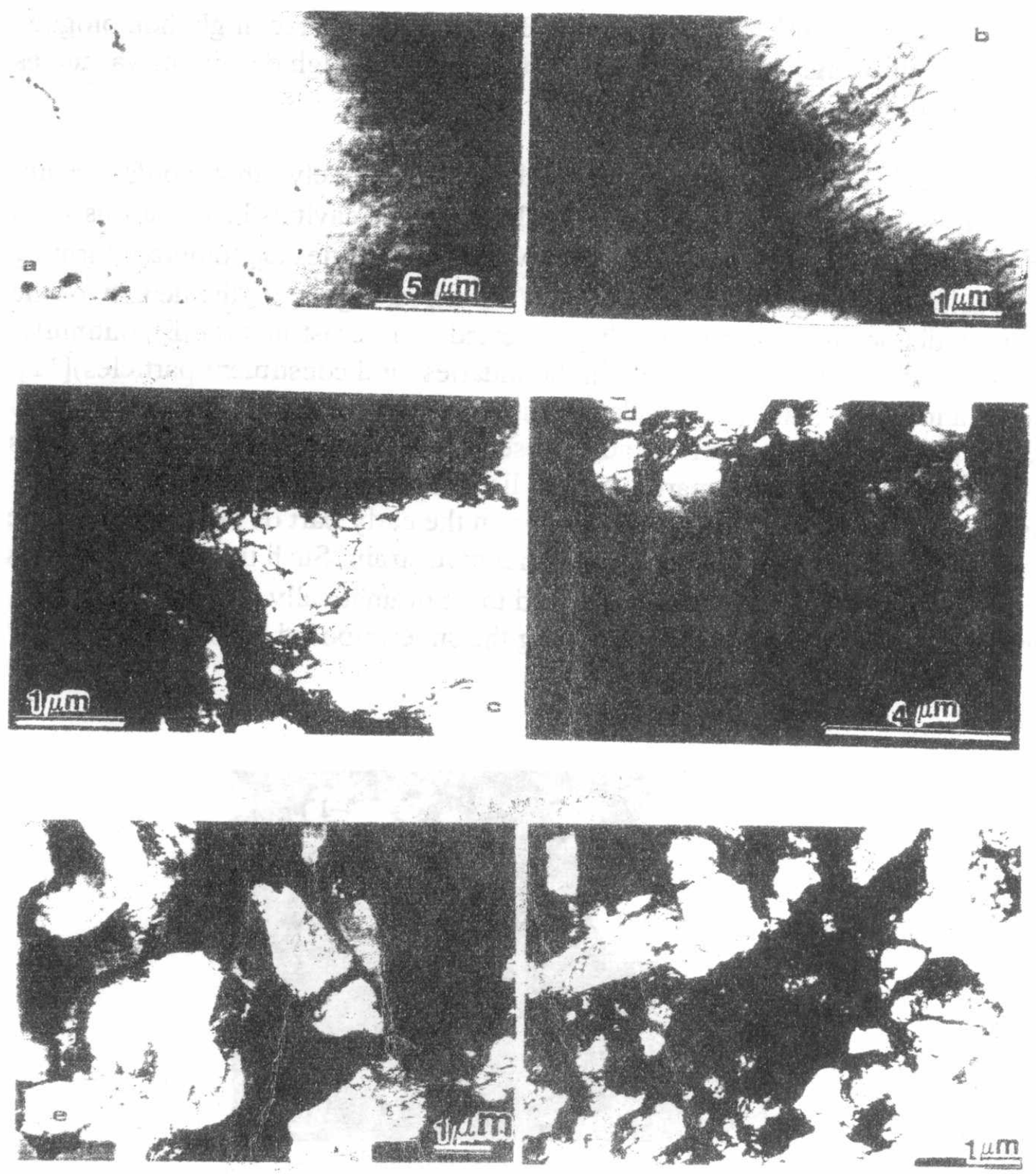

Fig. 7: TEM micrographs of cyclic crept specimens

$\left(\sigma_{\mathrm{ss}}=13.3 \mathrm{MPa}\right)$ hor: (a) virgin specimen.

(b, c, d, e and $f$ ) after cyclic creep for:

$0.1,1.0,4.0,7.0$ and 13 min. respectively. 
which accelerates the climb process. Briefly, the relative high homologous temperature, the high stacking fault energy and the high density of vacancies enhance the dynamic recovery.

Microstructure observations indicate albeit qualitatively that voids density increased with $\sigma_{\mathrm{ss}}$ as shown in Figs 3-5. The observed cavities have various sizes from less than $1 \mu \mathrm{m}$ to about $5 \mu \mathrm{m}$, moreover, some cavities agglomerate forming microcracks with length of $12 \mu \mathrm{m}$, Fig 6 . With increasing the $\sigma_{\mathrm{ss}}$ the density of the generated dislocations increase. They arrested at microstructural discontinuity, stress concentration sites, (i.e. grain boundaries and constituent particles)[11]. Concentration sites leading to crack initiation is therefore likely to occur, and it is possible that even the matrix cracks observed are associated with local stress raisers (such as constituent particles) that lie beneath the metal surface, Figs 3-5. Density of generated cavities is very low in the early part of the transient stage and it is observed to increase with cumulative strain. Such increase in cavities density with cumulative strain is observed to be dramatically at higher $\sigma_{\mathrm{ss}}$ levels. Then, failure is accelerated with increasing the superimposed tensile stress, Fig 1.

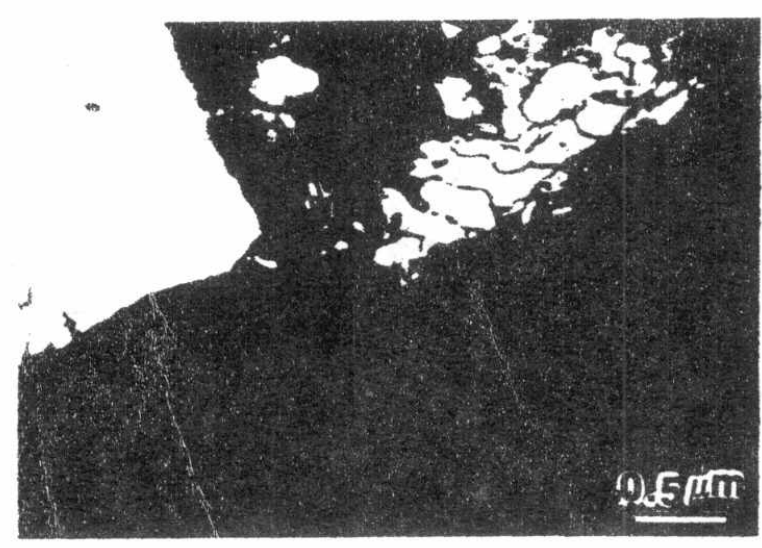

Fig. 8: TEM micrograph of cyclic crept specimen for 5 min. showing the dislocation structure of the evolved PSB, $\left(\sigma_{\mathrm{ss}}=13.3 \mathrm{MPa}\right)$.

\section{Fractography:}

In order to understand the fracture behavior in the present case, creep-fatigue interaction, it may be useful to invoke the fracture behavior in either creep or fatigue one at a time. In fatigue it has been reported that crack initiation is crystallographic at stage I and most likely to occur at free surface which 
$\lceil$ represents the obvious site because the lack of constrain in the surfaces grain means that dislocation substructures generated by cyclic straining extend out of the grains at the free surface to give microscopically irregular surface[10.11]. These dislocation structures are called persistent slip bands (PSB's), Fig 8. The crack growth step in fatigue in ductile metals is accomplished through fatigue striations, therefore, fracture surfaces of fatigued ductile metals is characterized by striations markings[10.11]. On the other side, it seems to be generally accepted that creep fracture occurs by the formation intergranular cavities or intergranular wedge cracks. However, they frequently occur in the same metal. It has been shown that wedge cracks tend to form at higher stresses and cavities at lower[10.13].

Creep-fatigue interaction of aluminum shows the formation of PSB's in several grains, Figs 3 and 4 . The presence of PSB's is observed at the whole applied superimposed positive stress levels, however, more slip bands formed at higher stresses. Concurrently, cavities are observed to be a common features in sections of cyclic crept specimens, Figs 3-6. At relatively high superimposed positive stress massive formation of cavities take place. Figure 6 shows a SEM micrograph demonstrating cavities distribution through the deformed structure as well as their transformation into microcracks. At triple points, grain boundary sliding results in geometrical incompatibilities that can be accommodate by vacancy diffusion to nucleate voids. On grain boundaries, voids are nucleated by vacancies diffusion, especially to matrix / precipitate interfaces and boundary sliding can assist this process. Inside grains vacancies can be formed as a result of the annihilation of edge dislocations which combined with cyclic deformation[14]. In the region near the PSB's/matrix interface where the supersaturating is highest, vacancy agglomerates may nucleate. Above a certain size vacancy agglomerates collapse into dislocation loops or form voids[14]. An example of the former process can be seen clearly in Fig 8. It may be speculated that voids at the $\mathrm{PSB} /$ matrix interface facilitate the propagation of a crack along the interface, since a new voids may form continuously ahead of the crack tip, Fig 8. Moreover, void/matrix interface represents a stress concentration site where stress concentrated and enhances coalescence of voids. Although such assumption doubtless occurs in static creep which produces typical ductile fracture surface it can not be completely excluded in the present case. The fracture surfaces micrographs show zone of a mixed fracture modes of ductile fracture and fatigue striations, Fig 9a. In fact the two modes of fracture, creep fracture and fatigue fracture are coexisting, Fig 9 . The obtained results show that the contribution of each mechanism during crack propagation stage is strongly depending on the value of the superimposed positive stress. Higher stress enhances the ductile creep mode in terms of voids formation and coalescence but does not suppress the fatigue fracture mechanism, striations, Fig 9, that observed to be lying along the planes of dimple walls. The observed striations along the plains of dimple walls could indicates that the voids formation due to creep strain 


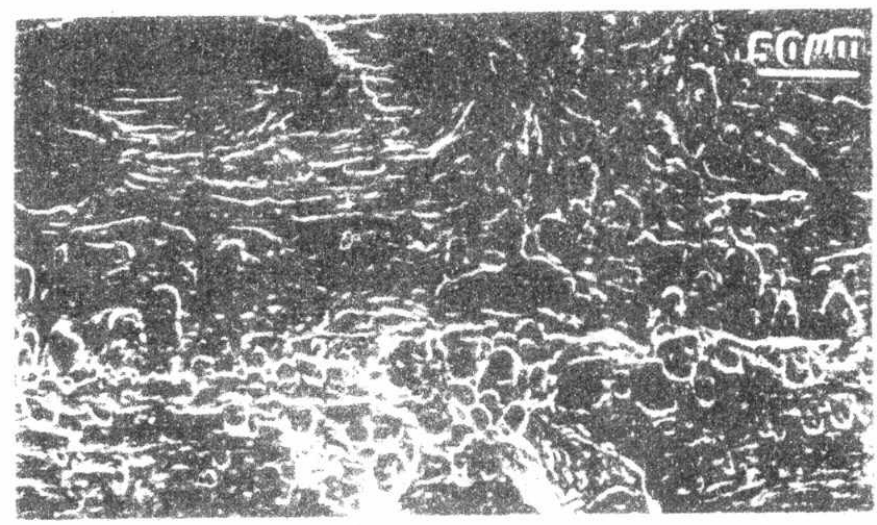

Fig. 9: Fatigue striations developed in the process of crack propagation along void wall, $\left(\sigma_{s s}=4.4\right.$ MPa $)$.

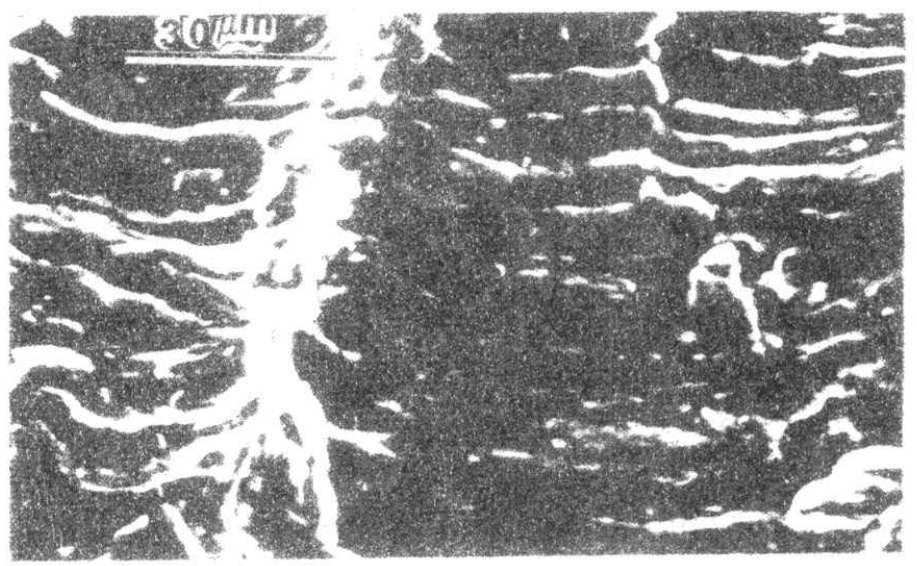

Fig. 10: Fatigue striations developed in the process of intergramular crach propagation, $\left(\sigma_{\mathrm{is}}=13.3 \mathrm{MPa}\right)$.

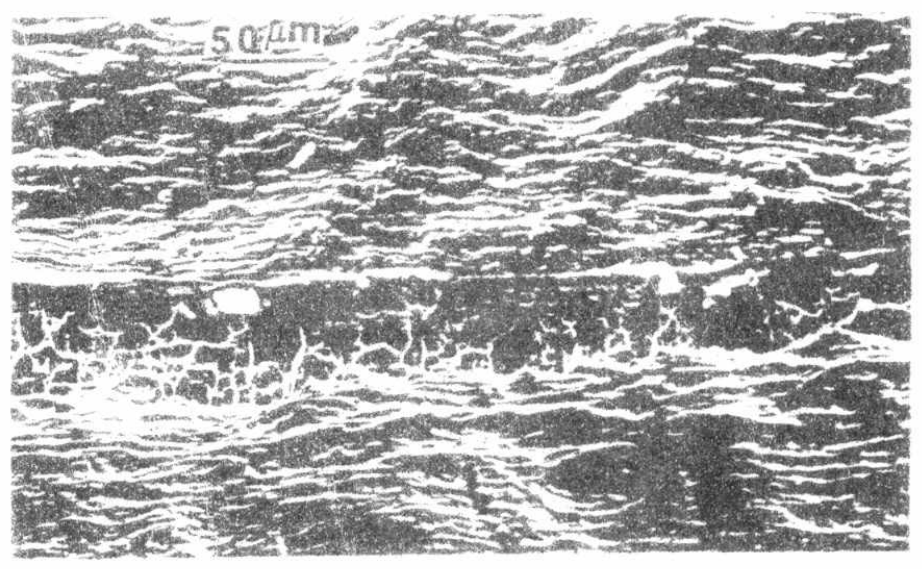

Fig. 11: Mountain and valley pattern displaying the characteristics of fracture surface caused by interaction between creep and fatigue, $\left(\sigma_{\mathrm{ss}}=22.2 \mathrm{MPa}\right)$ 
and/or cyclic straining will grow to a certain size prior to fatigue crack. The stress concentration in front of the fatigue crack tips could then transform these voids into microcracks, therefore, a combination of void to crack transformation and fatigue crack development will be mainly the control step of the fracture process rather than the nucleation growth and linkage of voids in the case of static creep The process of such voids in front of the fatigue crack tend to deform along the maximum shear stress direction and eventually join the normal fatigue crack. Moreover, the commercial pure aluminum, the present material, contains small amount of dispersoids which is likely to serve as obstacles and consequently voids formation sites. The interaction between fatigue cracks and dispersoids would produce many small steps with highs which is comparable to the size of particle-related microvoids. Such mechanism is possible for the observed mountain and valley patterns near the fatigue sources and also explain the presence of the striations perpendicular to the direction of the mountain and valley development, Fig 11.

The common feature noticed on all the fracture surfaces regardless the value of the superimposed positive stress is the propagation of the fatigue crack from strip's surfaces towards its interior, Figs 9-11. However, at the highest value of the superimposed positive stress, $22.2 \mathrm{MPa}$, which expected to enhance the creep ductile failure, fatigue failure is observed to be the dominant fracture mechanism. As the value of the superimposed positive stress decreased the fatigue striations appear more frequently and cover most of the fracture surface, Fig 9 . The failure was accomplished through fatigue crack propagation mechanism. The investigation of cyclic crept microstructure shows high density of voids in both grains' interior and along grain boundaries. These voids coalesced and formed microcracks, Fig 6. This step is most likely to be the first step in crack formation. Moreover, close observation of fatigue striations shows cavities at the tip of striations, Fig 10, that assisted fatigue crack propagation process.

\section{CONCLUSIONS}

Based on the obtained results of creep-fatigue interaction on aluminum at ambient temperature and the reported one of the high temperature creep and cyclic straining to a large cumulative strain at ambient temperature of aluminum $[8]$ it can be concluded that:

1. The creep-fatigue interaction is observed to strengthen the deformed material up to a saturation level depends on the amount of the superimposed positive stress at constant cyclic strain amplitude.

2. The development of the dislocation structure during creep-fatigue interaction passes through several stages ended by the evolution of cellular structure. 
Moreover, there is no difference could be detected between the evolved substructure in the present creep-fatigue interaction and the reported one of monotonic creep at high temperature or cyclic straining to a large cumulative strain at ambient temperature[8].

3. The fracture mechanisms are observed to operated in the present case, ductile creep and fatigue striation. Fatigue striations is found to be the dominant mechanism specially at low superimposed positive stress levels. Fatigue striations are observed to form at the strip's surface and propagate towards the strip's center where ductile fracture occurs.

\section{REFERENCES}

1. Baik, S. and Raj, R., Metall. Trans., 13 (1982) 1215-21.

2. Sigler, D., Montpetit, M.C. and Haworth, W.L., Metall. Trans., 14 (1983) 931-38.

3. Hong, K.T. and Naqm, S.W., J. Mater. Sci., 23 (1988) 117-81.

4. Ramadan, R.M., Bulletin TIMS, 59 (1992) 80-89.

5. Yang, Z.A. and Wang, Z., Metall. Trans., 24 (1993) 2083-93.

6. Zauter, R., Christ, H.-J. and Maughrabi, H., Metall. Trans., 25 (1994) 401-6.

7. Zauter, R., Christ, H.-J. and Maughrabi, H., Metall. Trans., 25 (1994) $407-$ 13.

8. Konig, G. and Blum, W., Acta Metall., 28 (1980) 519-37.

9. Yang, Z.A. and Wang, Z.G., Mater. Sci. Eng., 142A (1991) 25.

10. Ewalds, H.L. and Wanhill, R.J.H.,"Fracture Mechanics", Edward Arnold Pub. ,

London, (1984), 226-257.

11. Tomkins, B., "Fatigue: Mechanisms, In Creep and Fatigue in High Temperature alloys"' ed. by J. Bressers, Applied Sci. Pub., London, 1981, 111-125.

12. Lagnborg, R., Creep: Mechanisms and Theories, ibid, 41-71.

13. Edward, G.H. and Ashby, M.F., Acta Metall., 27 (1979) 1505-18.

14. Essmann, U., Gosele, U. and Mughrabi, H., Phil. Mag. 44(1981) 405-26. 